\title{
Patients as educators: Contemporary application of an old educational strategy to promote patient-centered care
}

\author{
J ill M. Terrien ${ }^{1}$, J anet Fraser Hale ${ }^{1,2}$ \\ 1. Graduate School of Nursing, University of Massachusetts Medical School, MA, USA. 2. Fatima College of Health Sciences, \\ Abu Dhabi, United Arab Emirates.
}

Correspondence: Jill M. Terrien. Address: Graduate School of Nursing, University of Massachusetts Medical School, 55 Lake Avenue, Worcester, MA, 01655 USA. Email: jill.terrien@umassmed.edu

Received: November 21, 2013

Accepted: December 23, 2013 Online Published: February 7, 2014

DOI : 10.5430/jnep.v4n4p104

URL: http://dx.doi.org/10.5430/jnep.v4n4p104

\section{Abstract}

Patients first. Patient-centered care. Patient-centered medical homes. The patient experience. Today, it is hard to miss the appeal for patient-centered care in US health care reform, as well as in national and professional publications. If patients are the focus, shouldn't they formally contribute to nursing and other health professions education? The earlier in their education students understand patients' perspectives, the better they can integrate patients' reality into their practice. Experiencing the health care maze through the perspective of a patient or family living with disability, cancer, chronic disease, or dementia has an indelible impact on a learner's practice. While simulation, standardized patients, and problembased learning are excellent educational strategies, patients as teachers in the classroom creatively, efficiently, and memorably bring life to multiple concepts and content areas far more effectively than an abstract case, lecture, and/or bulleted slides. This article presents a brief history of patient teachers, and the authors' experiences of integrating them into the nursing curriculum. Students enjoyed learning, participated enthusiastically, and evaluated these classes at the highest level. Patients found teaching empowering and were proud to teach future nurses.

\section{Key words}

Patients as teachers, Patients as educators, Patients as instructors, Patient-led teaching, Patient-centered, Experiential knowledge, Learning from patients

\section{I ntroduction}

Patients first! One cannot miss the focus on patients as US nurses seek to implement health care reform. The earlier nursing students understand patients' perspectives on illness, adherence, and the challenges of negotiating the health care environment, the better they can improve patients' experiences in a truly patient-centered health care system. Patients can profoundly enrich students' formal education as they share their experiences with their illnesses and with the health care system. Nursing students can be challenged to obtain a history from patients with dementia or trying to motivate individuals for health-behavior change. Nursing students are enlightened by experiencing the health care maze through the eyes of those living with disability, cancer, genetic disorders or dementia. Commonly employed health professions' teaching strategies are standardized patients and case studies; but an abstract case, bulleted slides, and/or a lecture are not 
as effective at bringing concepts and content to life as is a patient who is fully integrated into the class. Interacting directly with a patient in class is compelling and engaging for students and faculty alike. Patients describe the impact of disease pathophysiology and treatment on their lived experience and its effect on their quality of life. They share the challenges of behavior change and the trials of negotiating today's complex health care environment. Patients are proud to work with nurse educators to teach nurses to provide better care in practice.

Patient-centered care has been recommended by the Institute of Medicine as a competency for all health professionals to deliver as members of interdisciplinary teams ${ }^{[1]}$. In a recent report, the president of the IOM noted, "Since its foundation 40 years ago, the IOM has produced many reports echoing the theme of high-quality, safe, effective, evidence-based, and patient-centered care" ${ }^{[2]}$. The report preface notes, "Thus for nursing, health care reform provides an opportunity for the profession to meet the demand for safe, high-quality, patient-centered and equitable health care services. Nurses have key roles to play as team members and leaders for a reformed and better-integrated, patient-centered health care system" ${ }^{\text {[2] }}$. In the summary to this preface, the vision statement for health care notes that “...the health care system consistently demonstrates that it is responsive to individuals' needs and desires through the delivery of truly patient-centered care", "quality care that is patient centered", "patient-centered care across all settings", "patient-centered care models", and concludes "transform the health care system to provide...quality care that is accessible to all, patient centered and evidence based and leads to improved health outcomes" ${ }^{[2]}$.

This emphasis on patient-centered care is echoed by other professional groups. For example, the Interprofessional Education Collaborative has the vision of providing "safe, high quality, accessible, patient-centered care desired by all” " ${ }^{[3]}$. The IPEC also prioritizes "the interests of patients and populations at the center of inter-professional health care delivery" ${ }^{[3]}$. Similarly, the American Association of Colleges of Nursing states that "the master's-degree program prepares the graduate to... employ collaborative strategies in the design, coordination, and evaluation of patient-centered care” ${ }^{[4]}$. To improve the quality of patient care, the Robert Wood Johnson Foundation sponsors the Consumer Assessment of Healthcare Providers and Systems (CAHPS) program, which uses a standardized survey to collect data from patients about their experiences in health care settings ${ }^{[5]}$. The Institute for Healthcare Improvement held a 2-day workshop on "The Patient Experience: Improving Safety, Efficiency, and CAHPS Through Patient-Centered Care ${ }^{[6]}$. The Cleveland Clinic emphasizes its focus on patient-centered care with a designated Office of Patient Experience. Patients First is the guiding principle of the Cleveland Clinic ${ }^{[7]}$. Value Based Purchasing for U.S. hospitals will be evaluated on a total performance score of two weighted measures "clinical process of care domain" (70\%) and "patient experience of care domain" $(30 \%)^{[8]}$.

If health care is all about the patient, then shouldn't faculty actively incorporate patient instructors into formal educational processes to help students truly understand what it means to be patient centered from the patient's perspective? Shouldn't educators and students consider how patients perceive their health experience, what they need to make it better, how they want nurses to help fix the "system", how best to help them move from unhealthy to healthy behavior choices without compromising their cultural values, and how to support adherence and improve their health outcomes?

With involved patient educators in the classroom, students can learn the human and humane side of the pathophysiology, symptomatology, and treatment aspects of a disease process. They can also live vicariously through and understand the full extent of patients' experience of mental and/or medical illness, treatments, and/or disability(ies) as well as their impact on life goals, career path, family, and overall quality of life. Students gain insight into how patients perceive them as students and providers and how patients' cope with and manage issues, along with their struggles in negotiating today's complex and rapidly changing health care environment.

To illustrate the benefits of patients as teachers, the purpose of this article is to present a brief history of patient teachers and the authors' and other faculty's experiences of patients as active educators integrated into health professions curricula. Several examples within an academic health science center resulted in learning outcomes far exceeding the accom- 
plishment of class objectives. Findings suggest that having patients as active teachers in the classroom is a powerful interactive means for educating nurses to provide more patient-centered care.

\section{Background}

Patients have contributed to health professions education as passive and active educators for about 50 years, as predominantly discussed in the international and United States (US) medical literature. Recent US national publications and reports of health care reform initiatives focus on the importance of patients and patient-centered care as the US moves to increase access, lower costs, decrease disparities, and improve care quality and patient outcomes. In a recent review of the international literature, patients were found to be involved in medical, nursing, social work, and interprofessional student learning on a continuum ranging from passive with no learner interaction, as in a written case scenario, to more active with standardized patients to actual patients invited to share a disease experience ${ }^{[9]}$.

\subsection{Patients as passive educators}

Patients have served as passive teachers in medical and nursing education since the inception of health professions education ${ }^{[10-12]}$. Students need one-to-one, hands-on patient care to acquire the skills for direct care, as reflected by the large number of required clinical hours in their training. Having patients teach medical and nursing students is more common outside the US, particularly in the United Kingdom (UK) ${ }^{[11-18]}$. Clinical medical education has also employed patients passively as cases and exemplars since the $1960 \mathrm{~s}^{[9]}$. For example, patient cases may provide an interesting means to explain symptomatology, a disease process, or a response to a disease process ${ }^{[14]}$. Patients may be brought in as case exemplars for hospital grand rounds to teach medical students unique aspects of a disease or syndrome ${ }^{[15]}$. The case-based approach can involve a real patient case, one that is fabricated to draw in several features to meet learning objectives, or through a standardized patient program ${ }^{[11,12,19]}$. This article focuses on examples of actual patients as active educators.

\subsection{Patients as active educators}

In a review of 13 studies, patients had an active role in teaching medical students topics ranging from pediatric developmental disabilities to physical examination skills, particularly musculoskeletal assessment and male and female genitorectal examinations ${ }^{[12]}$. Patient educators may teach medical students clinical skills such as communicating or clinical interviewing developing interviewing skills in psychiatry, and communicating bad news to patients and families ${ }^{[11,15,16]}$.

Medical education has also supported student learning by having students spend an entire clinical rotation following a family with at least one family member suffering from a chronic disease or other impairment. This educational strategy is used in Israel to sensitize medical students to the importance of understanding the context of a disease within the family and community as well as to learn about relationship building and continuity of care ${ }^{[20]}$. Medical students meet with the family five times over a year; three times in their home and twice at medical visits, work, and/or school ${ }^{[20]}$.

Patients who actively instruct a group of students about care processes and serve as experts in their disease offer medical and nursing students the experience of learning these topics from the patient's perspective ${ }^{[14,15,17,21]}$. In fact, medical students' knowledge about the impact of rheumatoid arthritis on patients when taught by patients with the disease was at least as good as being taught by a physician, and students appreciated the patient's personal insight ${ }^{[17]}$. Nursing students' deep learning about the care of families of children diagnosed with cancer was fostered by listening to the parent of a child cancer survivor in the classroom ${ }^{[21]}$. Senior medical students who attended patient-led and faculty-led classes appreciated the realism of patients' experiences coupled with the faculty's biomedical knowledge that was generalizable to other cases ${ }^{[22]}$. Students liked learning the personal story behind the presentation of an interesting medical case and being able to ask "stupid" questions in a safe, protected environment where they were encouraged to seek answers to their difficult questions ${ }^{[22]}$. Similarly, $98 \%$ of medical students participating in interactive classroom education with patients with 
disabilities trained as educators reported greater overall awareness and sensitivity as well as better communication competency for future interactions with such patients ${ }^{[23]}$.

\subsection{I mpact of patients as educators}

Patients as educators have a positive impact on both patients and learners. Patients who participated as teachers for medical students found the experience positive and enjoyable; they appreciated sharing their knowledge and using their condition to contribute to educating future health care providers ${ }^{[12]}$. Some patients reported feeling empowered by the teaching opportunity ${ }^{[12]}$. Similarly, most patients enjoyed being part of the teaching experience, giving back and/or being the focus of attention ${ }^{[11,15,17,18]}$. Students valued practicing skills on patients and appreciated the unique opportunity to enhance skills and change their attitudes toward patients ${ }^{[10,12,23]}$. Students also enjoyed receiving constructive feedback from patients and reported increased respect for patients and improved understanding of the illness experience when taught by patients ${ }^{[10,12]}$. When patients are structured as experts in their disease, students may learn to genuinely value patients' contributions to student knowledge and experience ${ }^{[14]}$.

\subsection{Challenges and risks of patients as educators}

Using patients as an educational strategy also presents challenges and risks. Patients may use the role as an opportunity for secondary gain, e.g., to complain about the disease, health care system, or poor care, rather than to constructively teach clinicians how to improve care and/or the illness experience ${ }^{[15]}$. If the same patients are used repeatedly over time, the impact of their story may be lost with repetition ${ }^{[10]}$.

Another challenge may be training and motivating patients to participate as teachers. Some patients have been motivated by compensation at an hourly rate or reimbursement of expenses ${ }^{[12]}$. Faculty may fear that paying patients would interfere with genuine patient-student interactions and/or influence patients to say what they think is expected ${ }^{[10,12]}$.

Little information was found on patients as teachers in nursing education, particularly in non-clinical classes such as population health, professional role development, health care systems, and/or health promotion ${ }^{[24]}$. Furthermore, few studies were found on patients as active presenters or contributors to larger classes of health professions students nor studies on the relationship between the educational strategy of patients as educators to specific course objectives ${ }^{[10,21]}$. This gap in knowledge about structured involvement of patients in the teacher role may miss “... valuable strategies for the development of learning relationships that better promote reflexive and collaborative forms of professionalism” ${ }^{[14]}$.

Therefore, this article describes patients as active instructors and key participants in nursing student learning. At this small New England graduate school of nursing, patients as active educators are valued as an educational strategy to enhance student learning and improve their practice skills. This study was given exempt status from the Institutional Review Board.

\section{Process}

As co-coordinators of two required, didactic and skills based core graduate courses, we wished to increase the engagement of our students by promoting more exposure to reality based cases with whom they could immediately identify and interact. Based on the literature about patients as active educators we sought to develop interviewing skills, learn about a disease or socio-economic situation from the patients' perspective, and understand the impact of disease and adversity on the patient and family ${ }^{[14,15,17,21]}$. Additionally, we sought to link the reality of patients' experiences in partnership with faculty's biomedical knowledge that would be generalizable to other cases ${ }^{[22]}$. And, lastly we sought to increase the students' awareness and sensitivity to patients' reality ${ }^{[23]}$.

In an Advanced Health Assessment course, the authors invited a geriatric patient with mild dementia to participate in demonstrating a comprehensive health and social history to increase awareness of the challenges and rewards of inter- 
viewing an elder. The patient and daughter (caregiver and healthcare proxy) volunteered enthusiastically to provide this learning opportunity for the class of 40 students.

Jenny (a pseudonym) was a charming 90-year-old woman with dementia. We knew Jenny could be unpredictable and were unsure where this educational method might actually take the class given it was a live case demonstration that could not be scripted - much like most primary care and acute care encounters. We knew it would require both faculty and students to think quickly on their feet. Appreciating the risk of failure, we opted for the class to be an authentic, high quality learning opportunity that would allow students to manage the expected and unexpected in a safe and supported learning environment ${ }^{[22]}$.

Jenny was informed that she would answer students' questions to help them learn about communicating with elders to assess elders' unique health needs. As anticipated, Jenny's answers were totally unpredictable. According to Jenny's daughter, Jenny thrived on the attention and when puzzled, made up answers without losing a beat. She was totally candid in her responses to the students' questions and digressed at length with details and descriptions, forcing students to keep redirecting her back to the history while allowing her some latitude to share some of her life story and perceptions. Students were forced to think and respond professionally on their feet. They quickly learned to validate Jenny's responses with a reliable resource (Jenny's daughter) as Jenny was eager to please and agree with any answers nervously suggested by the students. Jenny was very believable, so students were always enlightened when Jenny's daughter would say, "Now Mom, that's not exactly how it was. Tell them why you needed to have surgery." Simultaneously, students learned to appreciate the challenges of succinctly and clearly documenting a long, detailed and sometimes rambling history. They quickly recognized the difficulties of completing a thorough history of an elder in a timely fashion; they came to understand the value of scheduling several appointments (or visits to the bedside) to gather information, and the challenges of gaining a focused history while engaging a patient to tell their story ${ }^{[11,15,16,22]}$. Thus, this teaching strategy pulled together many important teaching points about the process of health assessment and about caring for the elderly population.

Societal Forces Influencing Graduate Nursing Education and Practice is a core course addressing the evolution of the U.S. health care system and the multiple determinants of patient's and populations' health, on patient care, health outcomes, health policy, health care ethics, health promotion and disease prevention. A foundational component is also to assist students in appreciating the challenges of promoting positive health-behavior change in patients and populations.

For the latter we sought an educational strategy that would capture students' interest and demonstrate the difficulty of motivating patients to adopt positive health behaviors while at the same time building an understanding of social and economic determinants of health that influence their choices.

A gentleman who had lost 80 pounds over the previous few years came to mind as a potential patient educator for the class. When invited to address the rewards and challenges of his weight loss process Phil and his wife Rachel (pseudonyms) readily volunteered.

Phil asked how he should prepare for the class, but we believed, patient spontaneity in the educational role makes the experience more realistic and engaging for students ${ }^{[22,23]}$. We explained to Phil that once he had described how he lost the weight and maintained it, we would encourage further discussion with students to identify aspects of his life and environment along with any theoretical constructs of behavior change that may have contributed to his success. Students prepared for class by reviewing a faculty-developed on-line module that addressed health behavior-change theories. Again, we recognized that a possible risk with an unprompted speaker could result in failure to meet the session objectives, but we trusted in our good relationship with the 47 students who enthusiastically embraced the opportunity to participate in evaluating this interactive educational strategy. 
The students learned not only about Phil's suffering from a disabling condition for over 10 years before it was diagnosed, but also his hassles and disappointments with multiple providers across the country and health care systems. He described these frustrations from his experiences as an inpatient, a primary care patient, and a patient referred to multiple specialists, including psychiatrists, for answers, a diagnosis, and finally relief.

He then eloquently described the specific characteristics of the provider who carefully listened to him and finally "heard" what he was communicating. This provider reassured Phil and Rachel that Phil was not imagining his illness and that together they would find an explanation. Phil and Rachel both expressed how his interest in working with them provided them hope for the future. Phil also movingly described how the disease and his journey to find a diagnosis impacted and ended many of his life's dreams including his successful business and his ability to continue working and traveling with his beloved wife. Throughout the presentation, they both spoke. She sometimes augmented what he was saying or gently reminded him if he left out an important event or experience. She shared her experiences searching the literature and eventually the internet for leads to diagnosing his disease. Simultaneously, she also investigated healthy nutrition and other lifestyle changes including exercise programs for both of them. They were partners in their life and in their health care.

Students learned how the "special" provider in a caring health environment and Rachel inspired and supported Phil to lose weight through exercise and healthy eating, so he would have a better chance to stay alive while retaining as much quality of his life as they worked together to live with his diagnosis. Student feedback from both classes is summarized in the next section.

\section{Outcomes}

\subsection{Student class evaluations (formative)}

In addition to the formal summative course evaluations generated at the end of each semester, the authors request anonymous written feedback at the end of every class session to provide data for continuous quality improvement and "just-in-time" course adjustments as indicated. For both sessions on the anonymous evaluation forms, students highly rated the patient as educator component (Jenny: mean $=5.0$, Phil and Rachel: mean $=5.0$; range 1.0 [poor] to 5.0 [excellent]), demonstrating the educational strategy was well received. These numbers were supported by enthusiastic written feedback (see Table 1). In their informal verbal feedback as they were leaving both classes, students requested inviting more patient educators.

Specifically for "Jenny" students commented at the end of class how much they enjoyed the opportunity to apply communication and history-taking skills in this real-life, challenging, yet rewarding, experience similar to the findings in other studies ${ }^{[11,15,16,22]}$. They also reported that interacting with a real patient made more of an impact on their learning and commented on how much more difficult it was to keep the health interview focused than they had anticipated.

They appreciated the presence of a family member to help clarify specific areas of the history. They liked being able to practice "thinking on their feet" in a safe learning environment and appreciated their colleague's challenge to succinctly document a patient’s rambling interview ${ }^{[22]}$.

Students commented on how Phil and Rachel had eloquently incorporated every topic and concept from the course description and objectives and translated them into a learning experience that brought them all to life in a meaningful way. The students were able to "see" the impact of multiple determinants of health on patient choices and opportunities. Students were enlightened by how Phil and Rachel's experiences and frustration enhanced students understanding of the strengths and weaknesses of the current health care environment. Students felt they developed a much better understanding of the actual long term "lived" burden of ill health on a patient and family over time ${ }^{[14,15,17,21]}$. They also 
appreciated Phil and Rachel's suggestions for managing care with more focus on the patient and family. They appreciated learning the value of positive interactions and experiences with the health care system and how system support, hope and family love maintained them and motivated them to incorporate permanent healthy changes into their lifestyle. Students found the summary of the impact of Phil's health on the family's personal and professional goals, along with the forced change in direction of what they had envisioned for their retirement years to be enlightening. They said this forced them to think beyond just curing disease and caring for the patient and family. In response to the question for how the class could be improved, students suggested that background about Phil’s diagnosis in advance would have been helpful.

Table 1. Excerpts of qualitative feedback from students (formative)

\section{At what moment in class today were you most engaged as a learner?}

The entire time they were speaking.

Great to hear what people see in providers.

The "patient” was a great presentation. Hearing a patient perspective. The whole time.

When they were discussing how hard it was to navigate the system. The story behind the medical issue was great.

When the patient described "what" gave him faith in a good doctor!

Realizing how much of patient's health depends on provider and patient initiative and motivation.

"Patient as teacher" is not a new approach in medical and nursing education. Does this experience of hearing from the patient enhance your learning experience? Please comment.

Yes! I loved hearing their views and thinking about how I could apply that to practice. This helped me to learn to understand the patient and use that in health management. This also highlighted the idea of treating a family, not an individual. Clearly her [patient's wife] well-being is connected to her husband's so treating them as a unit was needed.

It is so impressive to hear how specific patient's memories are about health care providers - good or bad experiences - letting patient know you don't have the answer but will pursue it is so important.

This was wonderful! I think it is one of the most important things that someone in the medical field could experience. They are an absolutely adorable couple!

Yes it was great to hear their personal story, especially the closing of the discussion.

What action that anyone took in class today did you find most affirming or helpful?

When the patient described "what” gave him faith in a good doctor!

Realizing how much of patient's health depends on provider and patient initiative and motivation.

\subsection{Course evaluations (summative)}

Although specific feedback about the patient as educator had not been incorporated into the end of course evaluations, a number of students commented about it under the "strengths of the course”. For example, "loved the patient experience"; "Thanks for bringing in the patient. Having a real patient to interview made us all open our eyes to what we have to learn"; "The patient experience speakers were great. I would like greater development of this in class. Maybe a couple more patient speakers so we could work in small groups interviewing them.”

\section{Discussion/ Conclusion}

These examples of patients as educators demonstrate previous discussions and findings from the literature, but also demonstrated additional ways of incorporating patients into a variety of classes. Because our school budget could not remunerate our patient-educators, as others have reported we were encouraged by patients' feedback about the value and enjoyment they received from teaching nursing students ${ }^{[10,12]}$. Annually, our campus offers the Patient-as-Teacher award. Jenny was a recipient of this award one year. Phil and Rachel received flowers. We also provided them with formal thank you letters that include students' evaluations and comments. Phil and Rachel told the faculty and students, "Anything we can do to help future doctors and nurses be better at their jobs is well worth our time.” 


\section{Other examples of patients as educators}

Since the positive experiences of patient educators for the authors, other nursing faculty have incorporated patients as educators into their armamentaria of educational strategies. Examples include: a patient with a rare genetic disorder in Genetic, Genomics and Pharmacogenomics, a gentleman living with a liver transplant in a pre-licensure Transition to the Profession course, and a family with disabilities for a clinical class session focused on Caring for Patients with Special Needs. The goal for each was to put a human face to the lives and challenges of living with and caring for these special populations.

The genetics faculty wanted to help students better understand the patients' perspective, experience and often despair. As the patient described her experience of detection, diagnosis, and available therapeutic modalities, and how she managed decisions related to the choices available, students felt her emotions, including anger, depression, guilt, blame, shame, and hope. She shared the art of teaching patient and family members about the virtues of screening for genetic disorders, and the small and large gestures that make them seem human and humane to patients. Student evaluations revealed that she provided a context for not only living with the disorder, but also for the ethical decisions associated with screening options and difficult life decisions associated with an inheritable disorder, such as selecting a life partner and deciding whether to become pregnant. The class has been a powerful experience for both the patient educator and students.

In the Transitions course, in order to help students understand the field of organ transplantation, the liver transplant recipient discussed living with the diagnosis of a failing liver, placement on the transplant list, his journey through liver transplantation, and life beyond. He emphasized that throughout the continuum of care, it was the nurses who had the most significant impact on his recovery. He described how they "stayed with him" through his liver encephalopathy during hospitalization, carefully tending to him through days of diarrhea, helping him recover, and preparing him throughout for discharge and self-management post-transplant. He said the nurses motivated him to make healthy choices to maintain an optimal quality of life throughout the process and afterward. He shared the letter he wrote to the donor family articulating his humble thanks for giving him a second chance at life. His appreciation for his good fortune to be alive through the generous act of the donor and family was compelling and moving. Students appreciated understanding the trajectory and impact of liver failure, hope for and receipt of a donor organ and the recovery, and the importance of their role of nursing throughout this process including the procurement of organ donations.

The final exemplar is a colleague who each year brings in a family of two parents (both of whom had lived most of their lives in wheelchairs due to progressive paraplegia) with their fully able child to teach a medical school genetics course. The family's commanding story helped students appreciate the various definitions of "normal". Students were awed by how these parents normalized their own lives and that of their child. The family openly shared their rewards and struggles with various primary and specialty care providers within the health care system. Similar to the findings in a previous study, they described accessing the resources available to them, including health care professionals who took the extra step to learn how to best interact, support and advocate for a family with multiple disabilities and how to promote the family's desire for normalcy ${ }^{[23]}$.

In summary, patients as educators can be a powerful educational strategy for both patients and learners. As nursing education continues to include technology, simulations, and on-line courses, faculty must not lose sight of the potential value of learning about patients' lived experiences on students' immediate and long-term practice particularly in this era focusing on patient-centered care. The authors want to acknowledge the profound and enduring impact our patient educators have had on the education of our students. Hearing from our patients presented to students and faculty the reality of how the rapidly evolving US health care and reimbursement systems impact on patients, the clinical services available to them, their ability to adhere to recommendations, and the effects of illness and health-seeking on patients as individuals, family members, and community members. We encourage other nursing programs to consider re-creating the rich, patient-as-educator examples presented by the authors and the description of other exemplars for how to effectively convey multiple concepts by incorporating patient educators to engage and help students to not only achieve class 
objectives, but also to shape their future practice as health care professionals. Students quickly learn the value of providing humane care; identify areas to improve care and work processes, and the art and science of supporting patients to achieve optimal health outcomes through their care, leadership, and advocacy within the health care system. In addition to facilitating the achievement of course objectives, these patients have helped students understand the difference between pity, sympathy, and empathy and to move beyond feeling overwhelmed by the challenges they will face as practitioners by empowering them with practical knowledge and provider skills and behaviors to make a difference for their patients. We hope that this article gives readers pause to consider additional ways in which patient educators can enhance their classes. Whether or not patient teachers, in partnership with nurse educators, improve student and graduate practice as practitioners as well as patients' perceptions of having received patient-centered care awaits further study.

\section{Conflict of interest}

Neither author has any financial conflicts of interest.

\section{References}

[1] Institute of Medicine. Health Professions Education: A Bridge to Quality. The National Academies Press. 2003. Washington, DC. Available from: http://www.iom.edu/Reports/2003/Health-Professions-Education-A-Bridge-to-Quality.aspx (23 January 2014 date last accessed).

[2] Institute of Medicine. The Future of Nursing: Leading Change, Advancing Health. The National Academies Press. 2010. Washington, DC. Available from: http://www.iom.edu/Reports/2010/The-Future-of-Nursing-Leading-Change-Advancing-Health.aspx (23 January 2014 date last accessed).

[3] Interprofessional Education Collaborative. Core Competencies for Interprofessional Collaborative Practice. 2011. Interprofessional Education Collaborative, Washington, DC. Available from: http://www.aacn.nche.edu/education-resources/ipecreport.pdf (23 January 2014 date last accessed).

[4] American Association of Colleges of Nursing. The Essentials of Master's Education in Nursing. 2011. American Association of Colleges of Nursing, Washington, DC. Available from: http://www.aacn.nche.edu/education-resources/MastersEssentials11.pdf (23 January 2014 date last accessed).

[5] Robert Wood Johnson Foundation. The Benefits of CAHPS. 2012. Available from: http://www.rwjf.org/en/research-publications/find-rwjf-research/2012/04/the-benefits-of-cahps-.html (23 January 2014 date last accessed).

[6] Institute for Health Care Improvement. Conference on "The Patient Experience: Improving Safety, Efficiency, and CAHPS Through Patient-Centered Care.” 2013. http://www.ihi.org/offerings/Training/ThePatientExperience/April2013PatientExperience/Pages/default.aspx (23 January 2014 date last accessed).

[7] Cleveland Clinic. Patients first. 2013. Available from: http://my.clevelandclinic.org/patients-visitors/patient-experience/default.aspx (23 January 2014 date last accessed).

[8] Centers for Medicare and Medicaid Services. Open Door Forum: Hospital Value-Based Purchasing Fiscal Year 2013 Overview for Beneficiaries, Providers, and Stakeholders. (July 27, 2011).

http:/www.cms.gov/Medicare/Quality-Initiatives-Patient-Assessment-Instruments/hospital-value-based-purchasing/Downloads/ HospVBP_ODF_072711.pdf (23 January 2014 date last accessed). Available from:

[9] Towle, A., Bainbridge, L., Godolphin, W., Katz, A., Kline, C., Lown, B., Madularu, I., Solomon, P., Thistlethwaite, J. Active patient involvement in the education of health professionals. Medical Education. 2010; 44: 64-74. Doi:10.1111/j.1365-2923.2009.03530.

[10] Jha, V., Quinton, N.D., Bekker, H.L., Roberts, T.E. What educators and students really think about using patients as teachers in medical education: A qualitative study. Medical Education. 2009; 43(5): 449-456. PMID:19422492 http://dx.doi.org/10.1111/j.1365-2923.2009.03355.x

[11] Stacy R., Spencer, J. Patients as teachers: A qualitative study of patients' views on their role in a community-based undergraduate project. Medical Education. 1999; 33: 688-694. PMID:10476021 http://dx.doi.org/10.1046/j.1365-2923.1999.00454.x

[12] Wykurz, G., Kelly, D. Developing the role of patients as teachers: Literature review. British Medical Journal. 2002; 325: 818-821. PMID:12376445 http://dx.doi.org/10.1136/bmj.325.7368.818 
[13] Costello, J., Horne, M. Patients as teachers? An evaluative study of patients' involvement in classroom teaching. Nurse Education in Practice. 2001; 1(2): 94-102. PMID:19036250 http://dx.doi.org/10.1054/nepr.2001.0014

[14] Donetto, S. Medical students' views of power in doctor-patient interactions: The value of teacher-learner relationships. Medical Education. 2010; 44: 187-196. PMID: 20059675 http://dx.doi.org/10.1111/j.1365-2923.2009.03579.x

[15] Ikkos, G. Engaging patients as teachers of clinical interview skills. Psychiatric Bulletin. 2003; 27, 312-375. http://dx.doi.org/10.1192/pb.27.8.312

[16] Knox, J.D.E., Thomson, G.M. Breaking bad news: Medical undergraduate communication skills teaching and learning. Medical Education. 1989; 23: 258-261. PMID: 2725363 http://dx.doi.org/10.1111/j.1365-2923.1989.tb01541.x

[17] Phillpotts, C., Creamer, P., Andrews, T. Teaching medical students about chronic disease: Patient-led teaching in rheumatoid arthritis. Musculoskeletal Care. 2010; 8(1): 55-60. PMID: 20301228 http://dx.doi.org/10.1002/msc.169

[18] Salter, R.H. Learning from patients: Unfashionable, but effective. Postgraduate Medical Journal. 1996; 72: 385. PMID: 8935595 http://dx.doi.org/10.1136/pgmj.72.849.385

[19] Bokken, L., Rethans, J.J., Scherpbier, A.J., van der Vleuten, C.P. Strengths and weaknesses of simulated and real patients in the teaching of skills to medical students: A review. Simulation in Healthcare. 2008; 3(3): 161-169. PMID:19088660 http://dx.doi.org/10.1097/SIH.0b013e318182fc56

[20] Gaver, A., Borkan, J.M., Weingarten, M.A. Illness in context and families as teachers: A year-long project for medical students. Academic Medicine. 2005; 80 (5): 448-451. PMID:15851454 http://dx.doi.org/10.1097/00001888-200505000-00007

[21] Price, J. A parent in the classroom-a valuable way of fostering deep learning for the children's nursing student. Nursing Education in Practice. 2004; 4: 5-11. PMID:19038131 http://dx.doi.org/10.1016/S1471-5953(03)00005-2

[22] Henriksen, A., Ringsted, C. Medical students learning from patient-led teaching: experiential versus biomedical knowledge. Advances in Health Science Education. 2013. PMID:23591973

[23] Jain, S., Foster, E., Biery, N., Boyle, V. Patients with disabilities as teachers. Family Medicine. 2013; 45(1): 37-39. PMID:23334966

[24] Delpier, T. Cases 101: Learning to teach with cases. Nursing Education Perspectives. 2006; 27 (4): 204-209. PMID:16921806 